\title{
ORTHODONTIC EXTRUSION OF FRACTURED TOOTH: A CASE REPORT
}

\author{
Dr. Dashrath Kafle, ${ }^{1}$ Dr. Reetu Shrestha, ${ }^{2}$ Dr. Binam Sapkota, ${ }^{3}$ Dr. Nisha Acharya ${ }^{4}$ \\ 1. Lecturer, Dept of Orthodontics, Kathmandu University School of Medical Sciences, Dhulikhel \\ 2. Lecturer, Dept of Conservative and Endodontics, Kathmandu University School of Medical Sciences, Dhulikhel \\ 3. Lecturer, Dept of Prosthodontics, Kathmandu University School of Medical Sciences, Dhulikhel \\ 4. Resident, Dept of Conservative \& Endodontics, Universal College of Medical Sciences, Bhairawa
}

Correspondence : dashrath07@yahoo.com

\section{ABSTRACT}

Trauma to the aesthetic region of the mouth is very common. However the treatment of the traumatic injuries of the tooth depends upon various factors. Orthodontic extrusion of the fractured tooth is regularly practiced treatment modality. Orthodontic extrusion of such tooth is physiological, less invasive and long lasting. The extrusion of the tooth brings enough dental tissue to maintain the biological width and ferrule later into restorative/prosthetic phase. In this article we will report a case which was extruded $4 \mathrm{~mm}$ after endodontic treatment and restored by crown.

Key words: aesthetic, biological width, ferrule, orthodontic extrusion, trauma

\section{INTRODUCTION:}

Traumatic injury to the teeth is common problem in human being among which the trauma to the anterior teeth is most likely to occur. The anterior teeth are not so protected with soft tissue drape as it is seen in posterior region of the mouth. Because of this fact they have more chance of fracture. As the trauma to the anterior teeth is more common than the posterior teeth, the treatment need is also equally higher in anterior teeth being in the esthetic region. There are different modalities of the treatment of the fractured tooth. ${ }^{1,2}$ The treatment depends upon the level and direction of fracture, size and shape of the remaining tooth structure, root form, periodontal condition as well as age of the patient. The indication and contraindications of the orthodontic extrusion is well explained by Bach et al. ${ }^{3}$ If small portion of the crown is fractured, restorative treatment will suffice. If the bulk of the crown is fractured, the tooth may need post and core restoration after root canal therapy. However if small portion of the crown is remaining or the fracture of the tooth is below the gingival or alveolar crest, then the treatment with post and core only will not be stable. To maintain the health of the restored tooth, it is always very important to maintain the biological width of the tooth and maintain the ferrule. ${ }^{4}$ The restoration of the tooth fractured below the gingival margin is only possible if the orthodontic extrusion or surgical re- implantation of the tooth is done above the alveolar crest level. In some cases crown lengthening can also be considered. The surgical extrusion is a good and quick option but with this approach there is increased chance of ankylosis of the tooth. The orthodontic extrusion of the tooth does not have the risk of ankylosis. Orthodontic extrusion is more conservative and physiological than the surgical reposition. ${ }^{5}$ Crown lengthening can be a good option on posterior area but on the anterior teeth it may be associated with high gingival contour resulting in compromised esthetics. ${ }^{6}$

\section{CASE REPORT:}

A 23 years old male patient came to the Department of Dentistry, Dhulikhel Hospital, Kathmandu University Teaching Hospital, with the chief complain of fractured tooth following motorbike accident. On examination upper left central incisor was found to be fractured. The fracture was oblique starting from the cervical third of the crown labially upto subgingival area palatally. Rest of the other teeth seemed to be normal. The vestibule had minor abrasion near the philtrum area. There was not any other significant extra and intra oral lesion associated with the accident. Intra-oral peri-apical x-ray of the involved tooth showed normal root length. It did not reveal any fracture on root area. The treatment 
options explained to the patient were (a) extraction of the fractured tooth followed by prosthetic replacement (b) endodontic treatment and orthodontic extrusion of the tooth followed by crown (c) Endodontic treatment then crown lengthening followed by crown. The pros and cons of each of the treatment modalities were explained to the patient. The patient agreed upon the second treatment option.

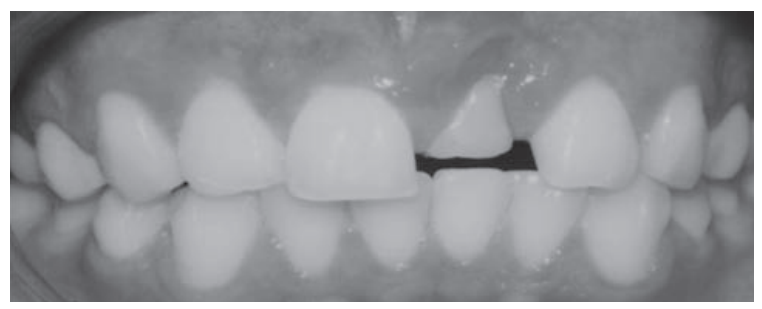

Fig 1: Fractured tooth before starting Extrusion

The endodontic treatment was started first. Because of the location of the fracture point, the canal was prepared by labial access. After thorough biomechanical preparation, the root canal was obturated by gutta percha points with lateral condensation technique.

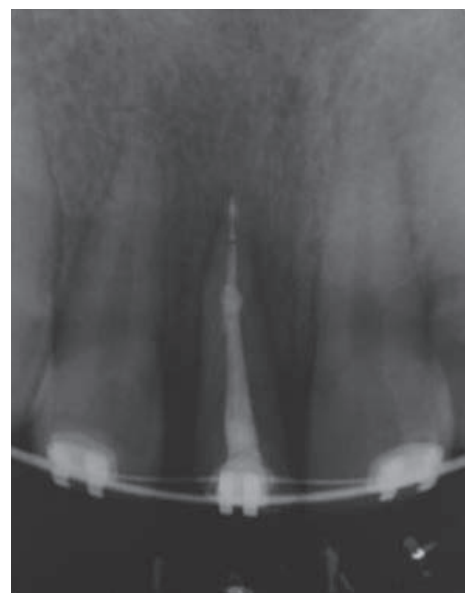

Fig 2: Post Obturation

The access cavity was filled with glass ionomer cement (GC, Japan) and the remaining coronal portion was built up by light cure composite resin for the purpose of bracket adhesion. The patient was then recalled after two weeks for orthodontic treatment.

Orthodontic treatment was started with Preadjusted edgewise orthodontic brackets (0.022 slot) with Roth prescription. The brackets were bonded on the upper arch from right first premolar to left first premolar on a straight line manner except on the tooth to be extruded. The purpose of such method of bonding was to ensure passive fit of the base arch wire. The fractured tooth was extruded by the piggyback mechanism. The anchorage was obtained from heavy arch wire. The extrusive force was obtained with 0.012 " nickel titanium wire. A total of
$4 \mathrm{~mm}$ of extrusion was obtained in 3 months duration. Then the tooth was restored with direct composite buildup during the time of retention. Later the composite restoration was replaced by porcelain fused to metal crown.
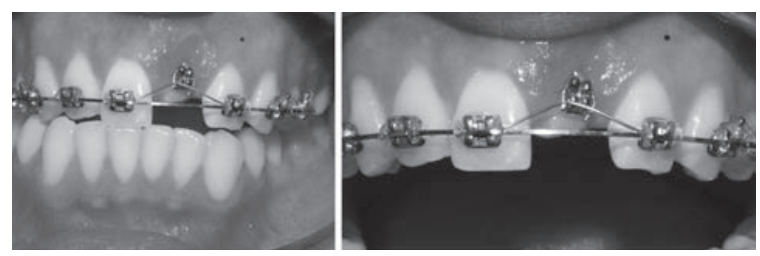

Fig 3: At the Start of orthodontic extrusion

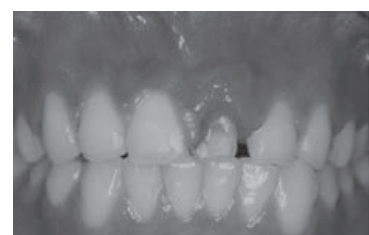

Fig 4: End of Extrusion

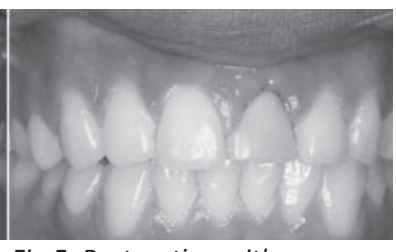

Fig 5: Restoration with crown

\section{DISCUSSION:}

Orthodontic extrusion is the most bio-favorable method of restoring the fractured tooth compared to extraction and prosthesis or surgical reposition or crown lengthening. ${ }^{5}$ Whether to extrude or not, it depends upon the level of fracture. If sufficient tooth material is remaining to maintain the ferrule, then extrusion is not needed. However if the restoration of the tooth violates the biological width or does not maintain the ferrule, then it is always better to extrude the fractured tooth. ${ }^{7}$ There are different methods of extrusion among which most common are orthodontic extrusion, ${ }^{8}$ magnetic extrusion. ${ }^{9-11}$ and surgical extrusion. ${ }^{12-15}$ Removable orthodontic appliances can also be applied to extrude the tooth but the success depends upon the patient compliance. So when the orthodontic extrusion is the treatment plan then fixed orthodontic appliance is the treatment of choice. The force can be applied via different mechanics such as piggyback wire (double wire technique), box loop, elastic chain, elastic thread or simply a flexible single arch wire. While using single arch wire there is always possibility of intrusion and flaring of remaining anchor teeth while extruding the fractured tooth. In our case to preserve the anchorage, we have successfully applied the double wire technique with $0.017 " \times 0.025^{\prime \prime}$ stainless steel base wire and 0.012 " nickel titanium wire.

\section{CONCLUSION:}

Orthodontic extrusion is a simple kind of tooth movement with minimum amount of force application yet very useful in certain circumstances. Short term extrusion of the fractured tooth can ensure the long term prognosis of the restoration of the tooth fractured sub-gingivally. 


\section{REFERENCES:}

1. Heithersay GS, Moule AJ. Anterior subgingival fractures: a review of treatment alternatives. Aust Dent, J. 1982 Dec;27(6):368-76.

2. Turker SB, Kose KN. Multidisciplinary approach in the treatment of subgingivally fractured anterior teeth. Dent Traumatol. 2008 Apr;24(2):239-43.

3. Bach N, Baylard JF, Voyer R. Orthodontic extrusion: periodontal considerations and applications. J Can Dent Assoc. 2004 Dec;70(11):775-80.

4. Biggerstaff RH, Sinks JH, Carazola JL. Orthodontic extrusion and biologic width realignment procedures: methods for reclaiming nonrestorable teeth. J Am Dent Assoc. 1986 Mar;112(3):345-8.

5. Kim SH, Tramontina VA, Ramos CM, Prado AM, Passanezi E, Greghi SL. Experimental surgical and orthodontic extrusion of teeth in dogs. Int J Periodontics Restorative Dent. 2009 Aug;29(4):435-43.

6. Simon JH. Root extrusion. Rationale and techniques. Dent Clin North Am. 1984 Oct;28(4):909-21.

7. Ross S, Dorfman HS, Palcanis KG. Orthodontic extrusion: a multidisciplinary treatment approach. J Am Dent Assoc. 1981 Feb;102(2):189-91.

8. Coval NM. Physiological orthodontic extrusion of fractured incisors. Chronicle. 1973 Jun;36(10):252-6.

9. Blechman AM. Magnetic force systems in orthodontics. Clinical results of a pilot study. Am J Orthod., 1985 Mar;87(3):201-10.

10. Blechman AM. Magnetic force in orthodontics. N Y State Dent J. 1990 Jun-Jul;56(6):47-8.

11. Mehl C, Wolfart S, Kern M. Orthodontic extrusion with magnets: a case report. Quintessence Int., 2008 May;39(5):371-9.

12. Fernandes Rodrigues CB, Kuga MC, Jara Gioris FA. [Surgical extrusion of roots for final restoration]. Rev Esp Endodoncia. 1988 May;6(1):17-23.

13. Caliskan MK. Surgical extrusion of a completely intruded permanent incisor. J Endod. 1998, May;24(5):381-4.

14. Caliskan MK. Surgical extrusion of a cervically root-fractured tooth after apexification treatment. J. Endod. 1999 Jul;25(7):509-13.

15. 15.Caliskan MK, Turkun M, Gomel M. Surgical extrusion of crown-root-fractured teeth: a clinical review., Int Endod J. 1999 Mar;32(2):146-51. 